\title{
Minimized Triple-Band Eight-Element Antenna Array for 5G Metal-frame Smartphone Applications
}

\author{
Jianlin Huang ${ }^{1}$, Zhuoni Chen ${ }^{1}$, Qibo Cai ${ }^{1}$, Tian Hong Loh ${ }^{2}$ and Gui Liu ${ }^{1, *}$ \\ 1 College of Electrical and Electronics Engineering, Wenzhou University, Wenzhou 325035, China; \\ 194511981414@stu.wzu.edu.cn (J.H.); 20451941037@stu.wzu.edu.cn (Z.C.); caiqibo@wzu.edu.cn (Q.C.) \\ 2 National Physical Laboratory, Teddington TW11 0LW, UK; tian.loh@npl.co.uk \\ * Correspondence: gliu@wzu.edu.cn
}

Citation: Huang, J.; Chen, Z.; Cai, Q.; Loh, T.H.; Liu, G. Minimized Triple-Band Eight-Element Antenna Array for 5G Metal-frame Smartphone Applications. Micromachines 2022, 13, 136. https:// doi.org/10.3390/mi13010136

Received: 22 November 2021 Accepted: 12 January 2022

Published: 15 January 2022

Publisher's Note: MDPI stays neutral with regard to jurisdictional claims in published maps and institutional affiliations.

Copyright: (c) 2022 by the authors. Licensee MDPI, Basel, Switzerland. This article is an open access article distributed under the terms and conditions of the Creative Commons Attribution (CC BY) license (https:// creativecommons.org/licenses/by/ $4.0 /)$.

\begin{abstract}
A multiple-input-multiple-output (MIMO) antenna array for triple-band 5G metal-frame smartphone applications is proposed in this paper. Each single antenna element consists of an S-shaped feeding strip and an L-shaped radiation strip on the metal frame. The dimension of the antenna element is only $6.5 \mathrm{~mm} \times 7 \mathrm{~mm}\left(0.076 \lambda_{0} \times 0.082 \lambda_{0}, \lambda_{0}\right.$ is the free-space wavelength at the frequency of $3.5 \mathrm{GHz}$ ). The $-6 \mathrm{~dB}$ impedance bandwidth of the proposed eight-antenna array can cover 3.3-3.8 GHz, 4.8-5 GHz, and 5.15-5.925 GHz. The evolution design and the analysis of the optimal parameters for a single antenna element are derived to investigate the principle of the antenna. The measured total efficiency is larger than $70 \%$. The measured isolation is better than $13 \mathrm{~dB}$. The measurements of the prototype agree well with the simulation results.
\end{abstract}

Keywords: 5G new radio (5G NR); sub-6 GHz; MIMO; triple-band antenna; metal-frame smartphone

\section{Introduction}

5G mobile communication technology has plenty of advantages, such as high communication capacity, high mass connection density, and high transmission rate. However, with the limited internal space of the universal smartphones, the number of antenna elements will be influenced. In order to solve this problem, each antenna element should be minimized [1-4], and operate at dual-band [5-12] or broadband [13-17]. By sharing a common grounding branch for the two adjacent antenna elements, a compact self-decoupled antenna pair was obtained in [1-3]. In [4], the height of the small printed circuit boards (PCBs) placed vertically to the system PCB is only $3.8 \mathrm{~mm}$, which is a novelty for compact antennas. By using a multi-slot decoupling technique, a dual-band eight-element antenna array is proposed in [5,12]. A single antenna element consisting of two radiators was presented for dual-band operation [6]. A folded monopole and a gap-coupled loop branch were combined together to obtain two broad bands [7]. By adjusting the impedance ratio of the stepped impedance resonators and the position of the microstrip feed line, a dual-band eight-antenna array is proposed for the 5G mobile application [8]. Two double-branch monopoles and a T-shaped decoupling stub were utilized for dual-band operation [9]. In [10], two different antenna elements, namely the folded L-shaped antenna and the couple-fed U-shaped antenna, were applied for LTE band 42 and 5.8-GHz WLAN band, respectively. A modified E-shaped strip on the corner of the frame was employed to realize a dual-band MIMO antenna [11]. Wideband MIMO antenna array can cover 5G sub-6 GHz bands, which was a good option for smartphones [13,15-17]. A systematic design of a high-performance eight-element antenna array was introduced for broadband operation [14].

On the other hand, isolation between antenna elements should be optimized for better performance [18-22]. A self-isolated MIMO antenna system was introduced in [18], which was achieved by introducing two vertical stubs into the original antenna element. By using a novel isolation technique named building block, a gap-coupled loop antenna and 
a loop antenna are isolated from each other [19]. A novel balanced open-slot antenna is designed as an array antenna element generating a balanced slot mode that can enhance the isolation [20]. The parasitic elements and defective ground can be used to obtain an outstanding isolation [21]. Different from the above isolation techniques, the author utilized a pattern diversity that two adjacent ports worked simultaneously but were excited at a relative phase in [22], which was proved to have good isolation.

This paper proposes a MIMO antenna array for triple-band 5G metal-frame smartphone applications. An S-shaped feeding strip and an L-shaped radiation strip on the frame are utilized to achieve good performance. By using an S-shaped feeding strip, we can improve the bandwidth of the lower frequency band with minimized size. The structure of the antenna element is only $6.5 \mathrm{~mm} \times 7 \mathrm{~mm}$, which is the innovative point of this paper. The $-6 \mathrm{~dB}$ impedance bandwidth of the proposed eight-antenna array can fully cover 3.3-3.8 GHz, 4.8-5 GHz, and 5.15-5.925 GHz frequency bands.

\section{Antenna Geometry}

The detailed geometry of the proposed triple-band eight-element array for 5G metalframe smartphone applications is shown in Figure 1. There are two kinds of PCBs in the proposed MIMO antenna, including the mainboard and two sideboards. The dimensions of the mainboard and the sideboards are $150 \mathrm{~mm} \times 75 \mathrm{~mm} \times 0.8 \mathrm{~mm}$ and $150 \mathrm{~mm} \times 6.2 \mathrm{~mm} \times$ $0.8 \mathrm{~mm}$, respectively. The system ground plane is printed on the bottom of the mainboard. In addition, there is a metal frame on the edge plate of each sideboard. The eight antenna elements are printed on the two sideboards which are placed vertically to the mainboard. The sideboards and mainboard are all printed on a FR4 substrate with $\varepsilon_{\mathrm{r}}=4.4$, and $\tan \delta=0.02$, which are bonded to each other by tin. Each antenna is fed with a $50-\Omega$ microstrip feedline and a SMA connector via a hole from the backside of the main substrate. The proposed antenna array has advantages of small volume (the single antenna element is only $6.5 \mathrm{~mm} \times 7 \mathrm{~mm}$ ) and tripleband operation (the $-6 \mathrm{~dB}$ impedance bandwidth can fully cover $3.3-3.8 \mathrm{GHz}, 4.8-5 \mathrm{GHz}$, and $5.15-5.925 \mathrm{GHz}$ ). Furthermore, a side view of the four antenna elements is given in Figure $1 \mathrm{~b}$. The values of the parameters are: $\mathrm{L}=6.5 \mathrm{~mm} ; \mathrm{H}=7 \mathrm{~mm} ; \mathrm{D}=22.5 \mathrm{~mm} ; \mathrm{d} 34=\mathrm{d} 12=21 \mathrm{~mm}$; $\mathrm{d} 23=37 \mathrm{~mm} ; \mathrm{D} 34=\mathrm{D} 12=27.5 \mathrm{~mm}$; and D23 = $46 \mathrm{~mm}$.

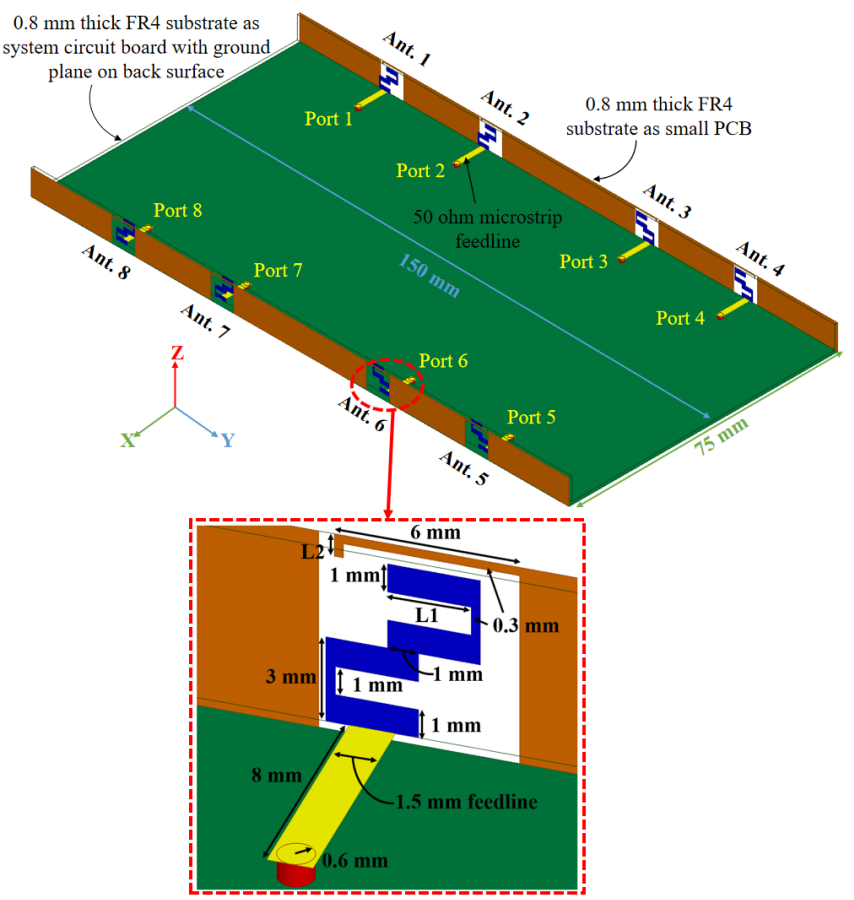

(a)

Figure 1. Cont. 


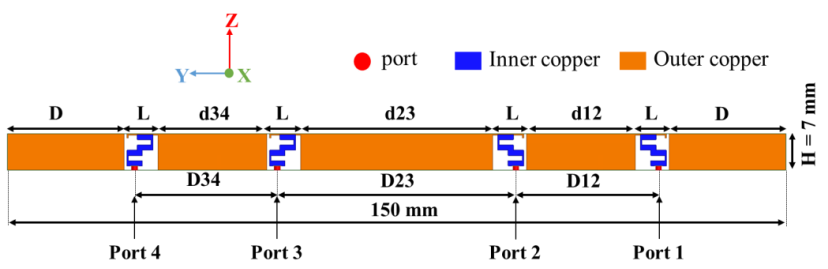

(b)

Figure 1. Geometry and dimensions of the proposed triple-band eight-element antenna array in millimeters: (a) Prospective view; (b) Side view.

\section{Antenna Analysis}

In order to understand the mechanism of the proposed MIMO antenna system, the design evolution, simulated surface current distribution, and the optimal parameter analysis of the antenna element have been studied.

In Figure 2, Case 1 is a simple monopole. By cutting two rectangle slots on the strips of antenna of Case 1, the antenna of Case 2 is obtained. By adding an L-shaped radiation strip on the frame of antenna of Case 1, the antenna of Case 3 is formed that has the character of single band at $3.8 \mathrm{GHz}$. By cutting a rectangle slot of the antenna of Case 3, the antenna of Case 4 is produced, which gets a better performance compared to that of Case 3 . While cutting another rectangle slot of antenna of Case 3, the antenna of Case 5 is formed. By combining the superiority of antennas of Case 4 and Case 5, the proposed antenna element is proposed, which has two resonance points that can fully cover $3.3-3.8 \mathrm{GHz}$ in the lower frequency band and $4.8-5.925 \mathrm{GHz}$ in the higher frequency band.

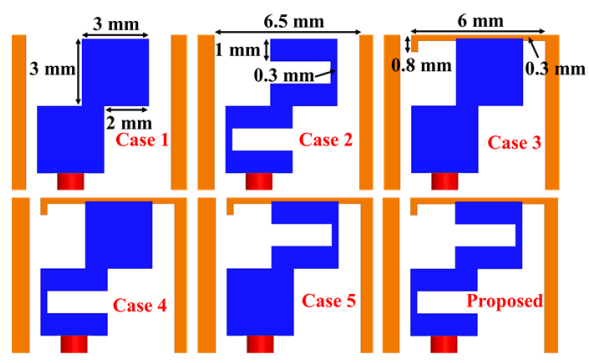

(a)

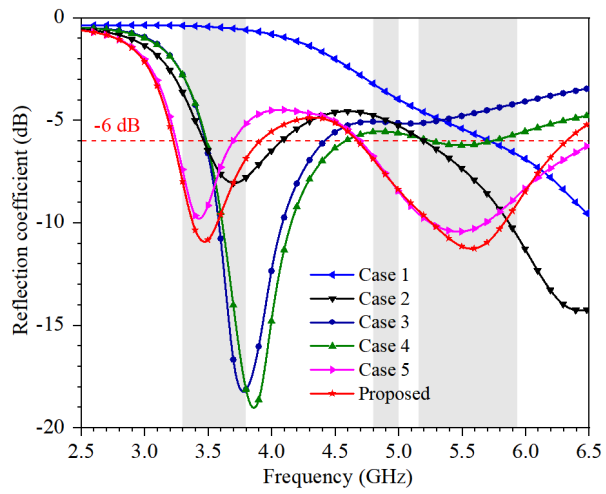

(b)

Figure 2. Design evolution of antenna element: (a) The evolution shapes; (b) The reflection coefficient.

Figure 3 show the surface current distribution simulated at $3.5 \mathrm{GHz}, 4.9 \mathrm{GHz}$, and $5.5 \mathrm{GHz}$. The distribution of the surface current at $3.5 \mathrm{GHz}$ is mainly concentrated at the right side of the frame. On the contrary, the surface current at $4.9 \mathrm{GHz}$ is focused on the left 
side of the frame. However, the surface current distribution at $5.5 \mathrm{GHz}$ is on the left and top sides.
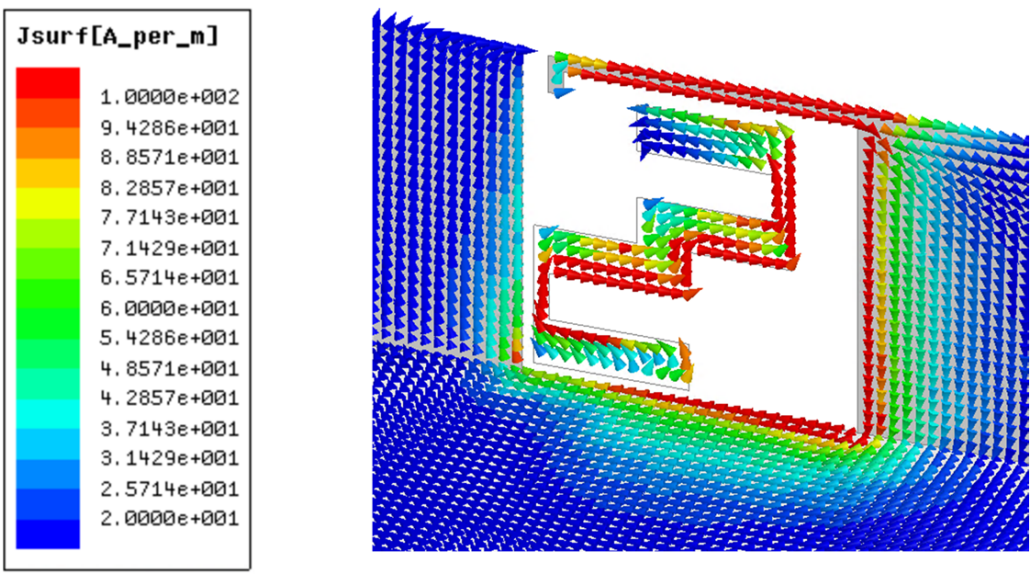

(a)

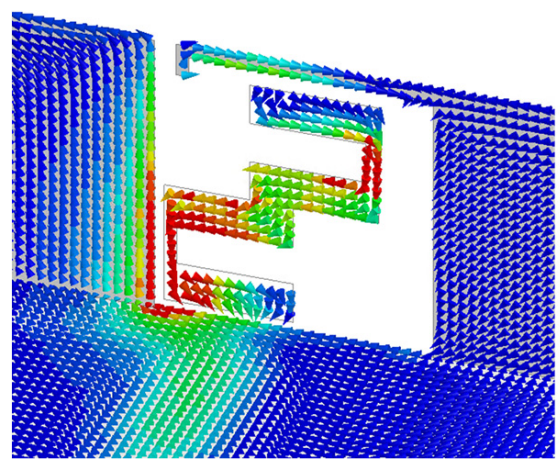

(b)

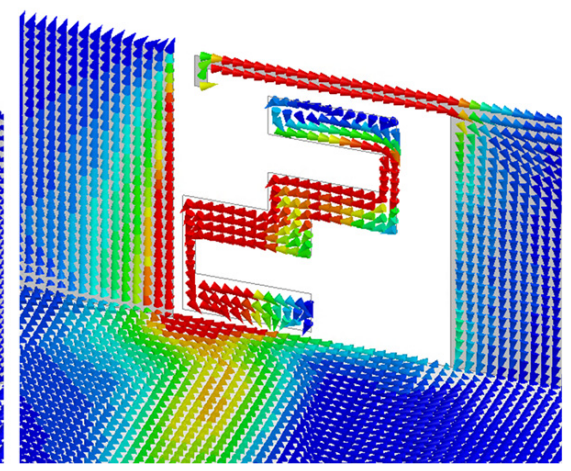

(c)

Figure 3. Simulated surface current distribution at (a) $3.5 \mathrm{GHz}$, (b) $4.9 \mathrm{GHz}$, and (c) $5.5 \mathrm{GHz}$.

Figure 4 shows the simulated reflection coefficient as a function of L1 and L2. The value of L1 can be effectively used to change the resonant frequency of the lower frequency band, while the value of L2 can be utilized to tune the resonant frequencies of both the lower and higher frequency band.

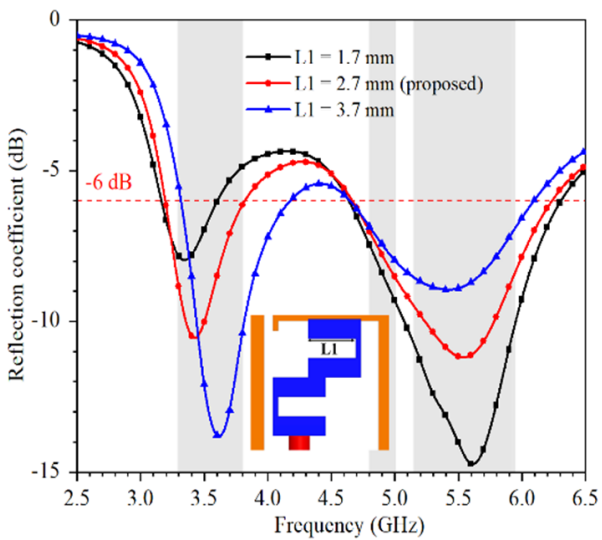

(a)

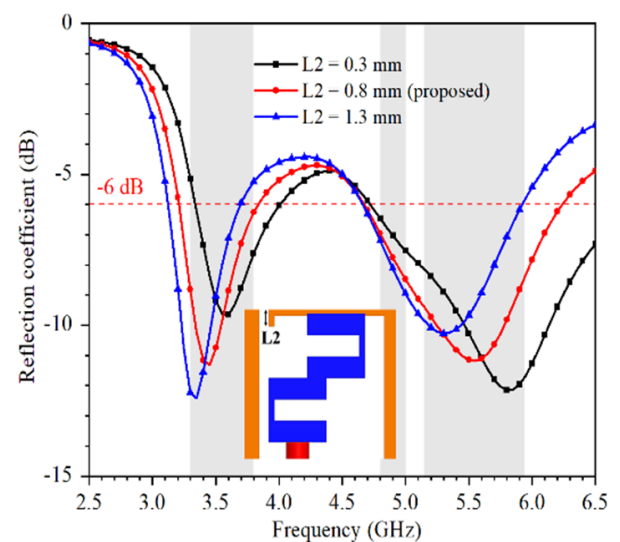

(b)

Figure 4. The simulated reflection coefficient as a function of (a) L1, (b) L2. 


\section{Experimental Results and Discussion}

To verify the proposed design, an antenna prototype was fabricated using the optimized dimensions described in Figure 1. Figure 5 is a photograph of the measurement setup.

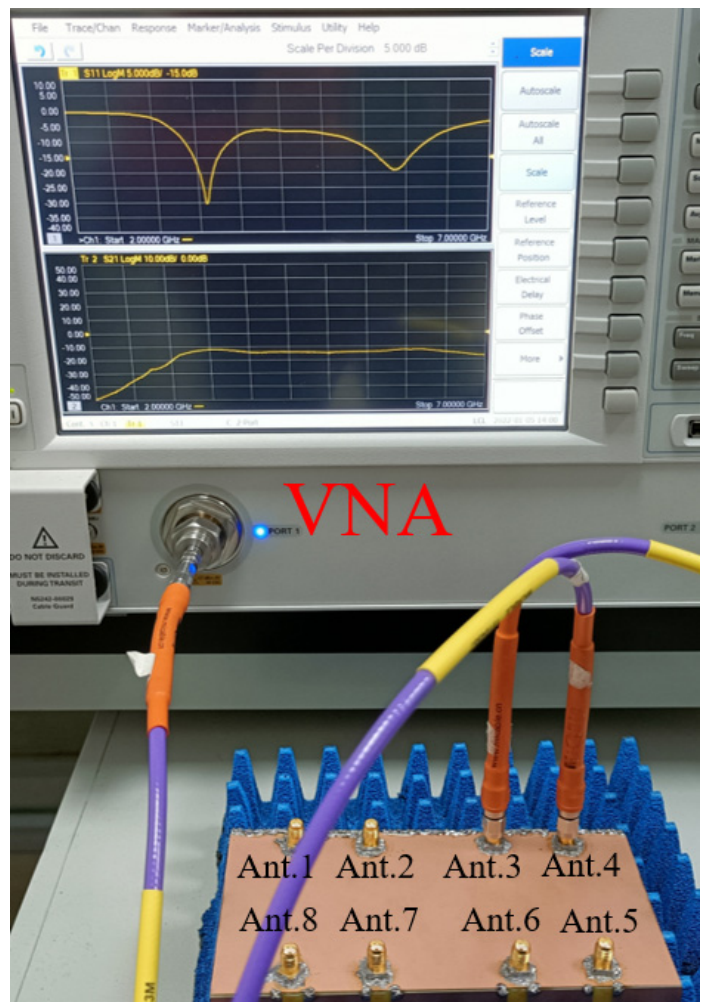

(a)

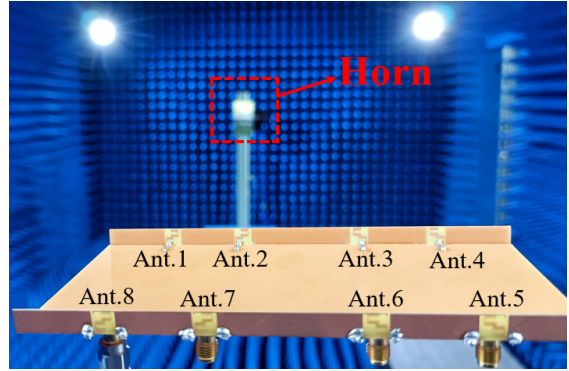

(b)

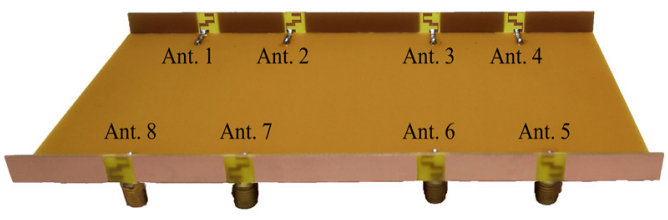

(c)

Figure 5. Photograph of the measurement setup; (a) vector network analyzer; (b) anechoic chamber; (c) fabricated antenna.

Figure 6 shows the simulated and measured coefficients. The antenna is measured by Keysight Vector Network Analyzer N5224A. It can be seen that the simulated and measured bandwidth can cover 3.3-3.8 GHz, 4.8-5 GHz, and 5.15-5.925 GHz. The isolation between different ports is larger than $13 \mathrm{~dB}$. The slight frequency offset is due to excess solder. 


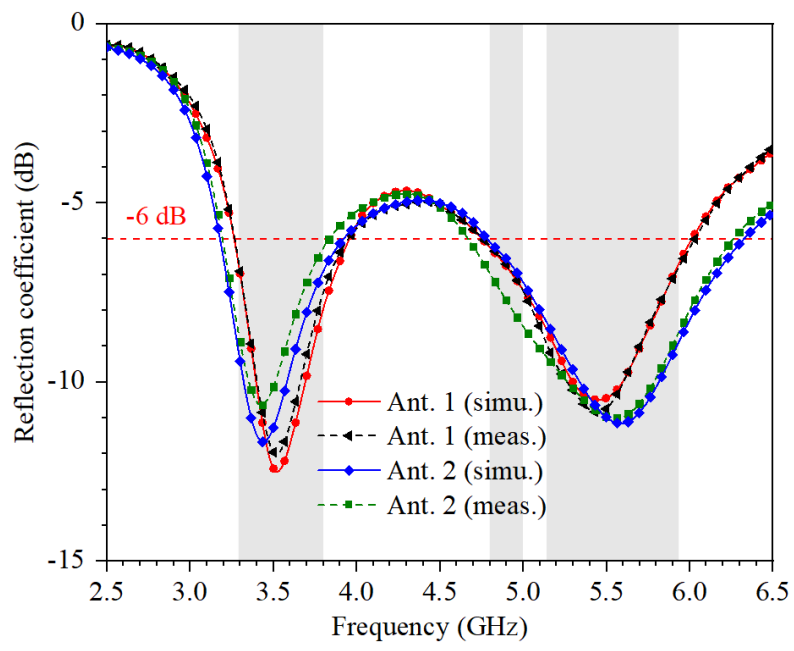

(a)

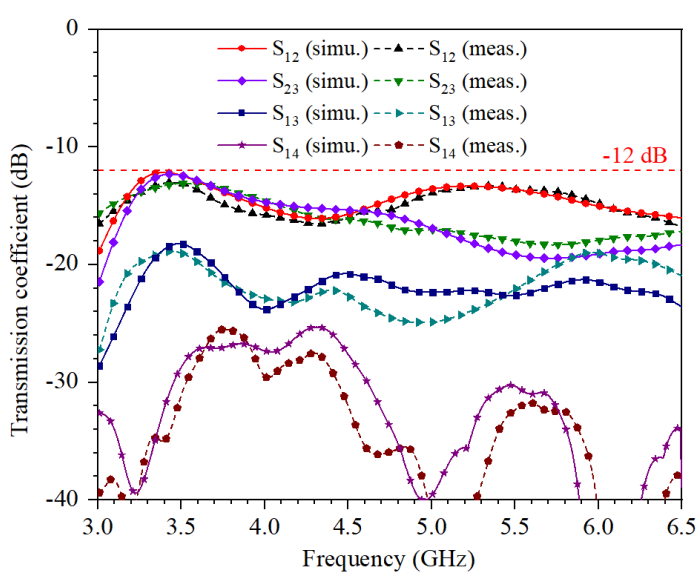

(b)

Figure 6. Simulated and measured coefficients of the proposed antenna array: (a) simulated and measured reflection coefficient; (b) simulated and measured transmission coefficient.

Figure 7 shows all measured total efficiencies which are larger than $70 \%$. The inconsistent efficiency of symmetrical antennas is due to the current skin effect caused by excess solder.

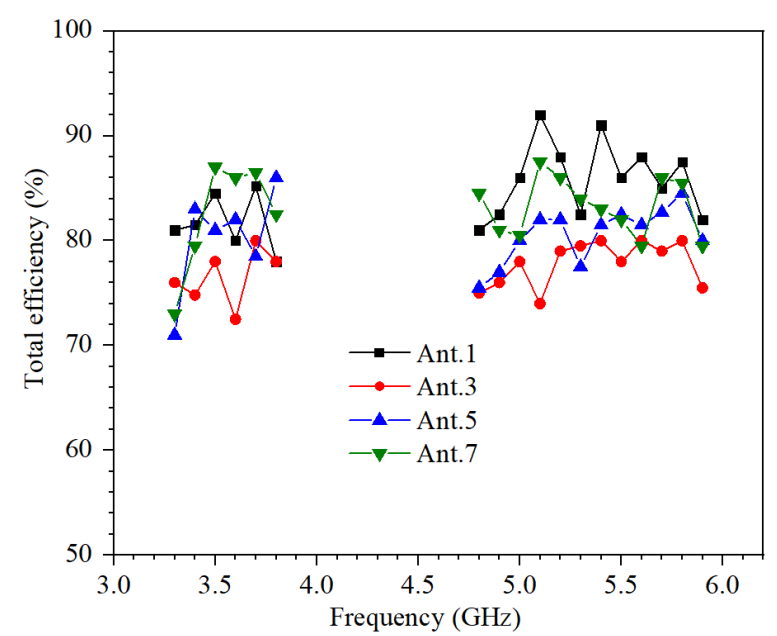

Figure 7. Measured total efficiencies of Ant. 1,2,3,4. 
In this study, the imaginary part and real part of the S-parameters are measured by VNA, and the calculated envelope correlation coefficient (ECC) of the proposed eightantenna MIMO system according to Equation (1).

$$
\mathrm{ECC}=\frac{\iint_{4 \pi} \mathrm{A}_{\mathrm{ij}}(\theta, \phi) \sin (\theta) d \theta d \phi}{\sqrt{\iint_{4 \pi} \mathrm{A}_{\mathrm{ii}}(\theta, \phi) \sin (\theta) d \theta d \phi \iint_{4 \pi} \mathrm{A}_{\mathrm{ij}}(\theta, \phi) \sin (\theta) d \theta d \phi}}
$$

The calculated ECC of the proposed MIMO antenna system is shown in Figure 8. The values of ECC in the operating frequency bands are smaller than 0.09 .

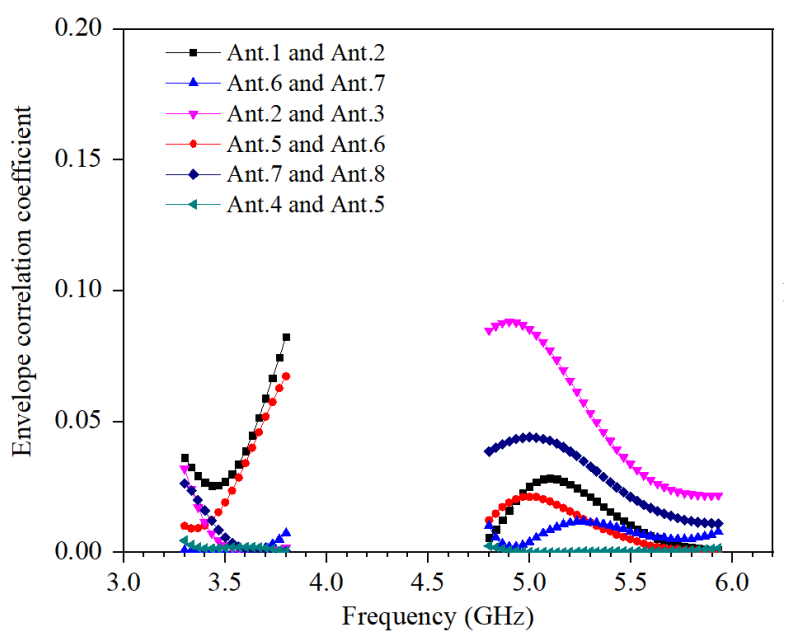

Figure 8. Calculated ECC.

The calculated diversity gain (DG) is related to ECC in Equation (2).

$$
\mathrm{DG}=10(\mathrm{~dB}) \times \sqrt{1-|\mathrm{ECC}|^{2}}
$$

The calculated DG of the proposed MIMO antenna system is shown in Figure 9. The values of DG in the operating frequency bands are greater than 9.96.

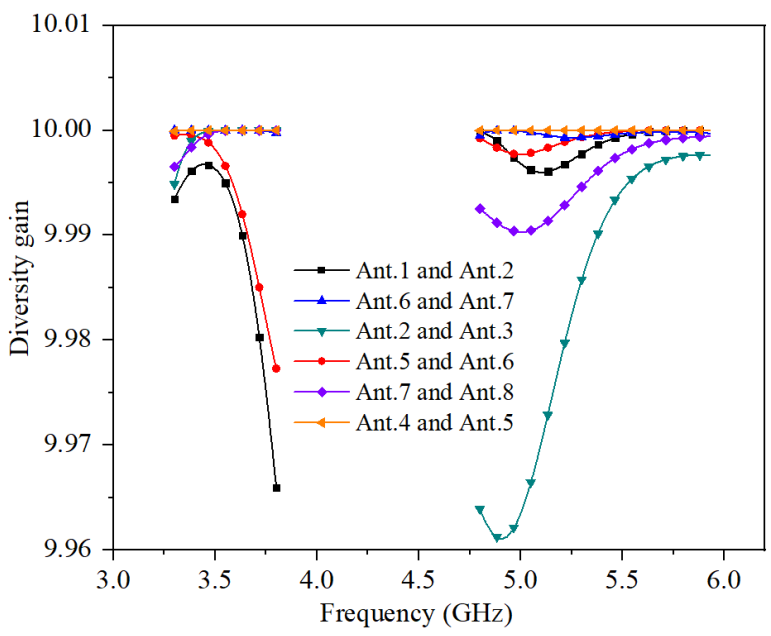

Figure 9. Calculated DG.

The multiplexing efficiency (ME) is related to ECC in Equation (3). $\eta_{1}$ and $\eta_{2}$ are total efficiencies in Figure 7.

$$
\mathrm{ME}=\sqrt{\eta_{1} \eta_{2}\left(1-|\mathrm{ECC}|^{2}\right)}
$$


The calculated ME of the proposed MIMO antenna system is shown in Figure 10. The values of ME in the operating frequency bands are greater than $70 \%$.

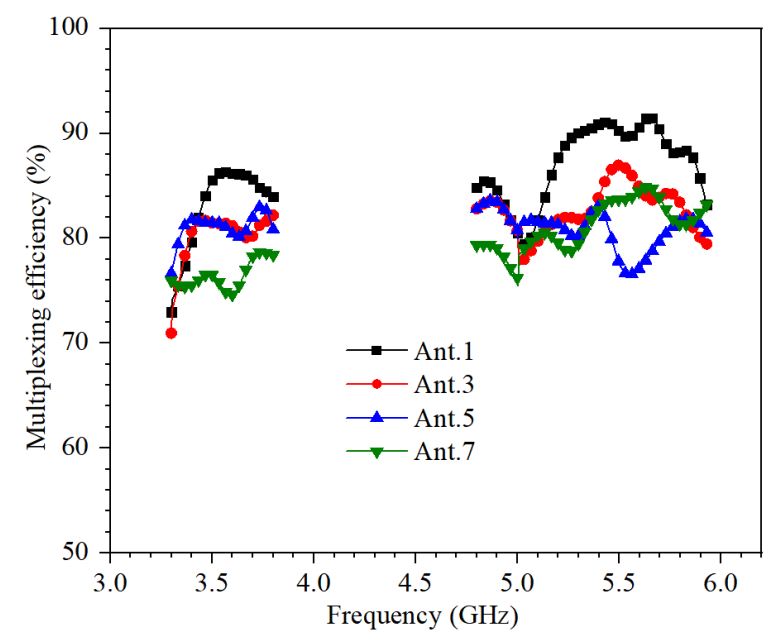

Figure 10. Calculated ME.

The channel capacity loss (CCL) is calculated from S-parameters using MATLAB in Equations (4) and (5).

$$
\begin{gathered}
\text { CCL }=-\log _{2}[\operatorname{det}(\Psi)], \Psi=\left[\begin{array}{ll}
P_{11} & P_{12} \\
P_{21} & P_{22}
\end{array}\right] \\
P_{i i}=1-\left|S_{i i}\right|^{2}-\left|S_{i j}\right|^{2}, P_{i j}=-\left(S_{i i}{ }^{*} S_{i j}+S_{j i}{ }^{*} S_{j j}\right) ; \text { for } \mathrm{i}, j=1 \text { or } 2
\end{gathered}
$$

The calculated CCL of the proposed MIMO antenna system is shown in Figure 11. The values of CCL in the operating frequency bands are smaller than 0.5 .

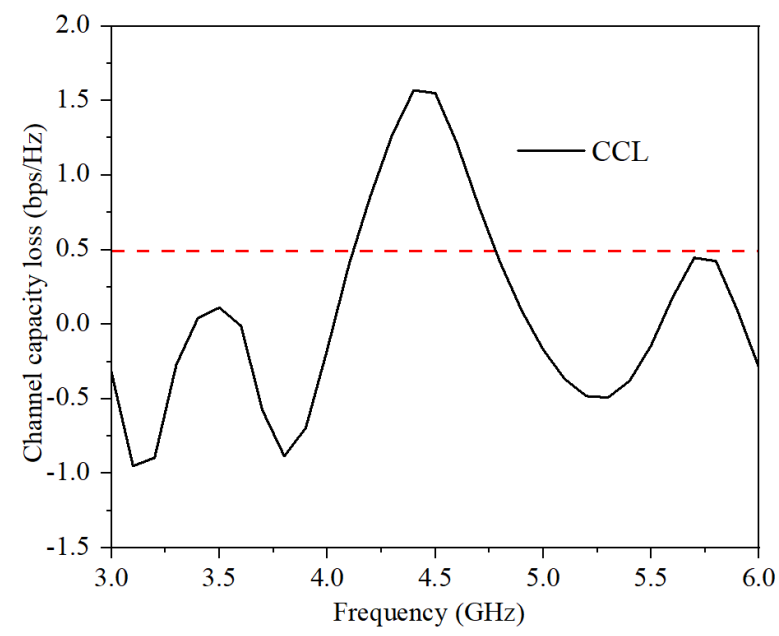

Figure 11. Calculated DG.

The total active reflection coefficient (TARC) is calculated from S-parameters in Equation (6).

$$
\text { TARC }=\sqrt{\frac{\left(\mathrm{S}_{11}+\mathrm{S}_{21} *\right)^{2}+\left(\mathrm{S}_{21}+\mathrm{S}_{22}\right)^{2}}{2}}
$$

The calculated TARC of the proposed MIMO antenna system is shown in Figure 12. The values of TARC in the operating frequency bands are smaller than $-10 \mathrm{~dB}$. 


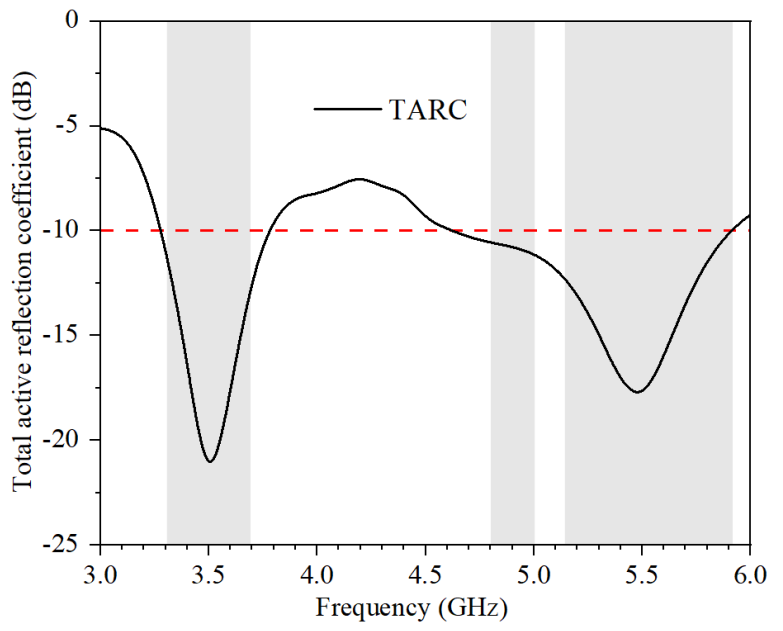

Figure 12. Calculated TARC.

The radiation patterns of the proposed antenna element at $3.5 \mathrm{GHz}, 4.9 \mathrm{GHz}$, and $5.5 \mathrm{GHz}$ are shown in Figure 13. The measured co-pol and cross-pol are represented by solid and dashed lines, respectively. The cross-pol of all antennas is smaller than the co-pol. The co-pol and cross-pol of the same antenna are different at disparate frequency points. Since Ant.1 and Ant.2 have the same shape and different positions, radiation patterns are slightly similar, but not identical.

Ant. 1

Ant. 2

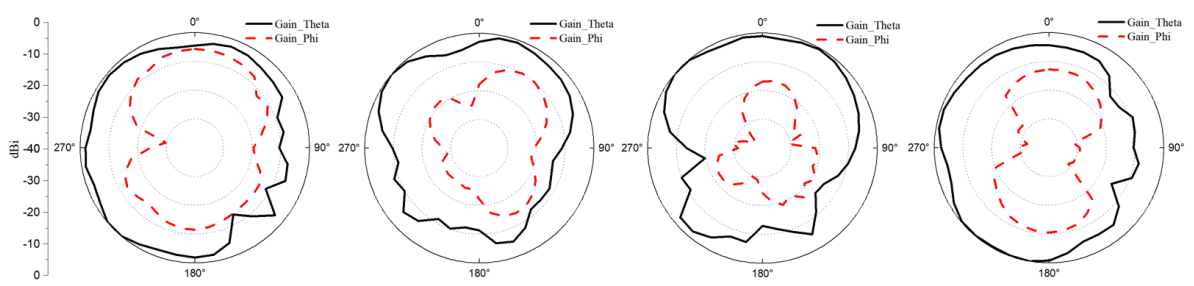

(a)

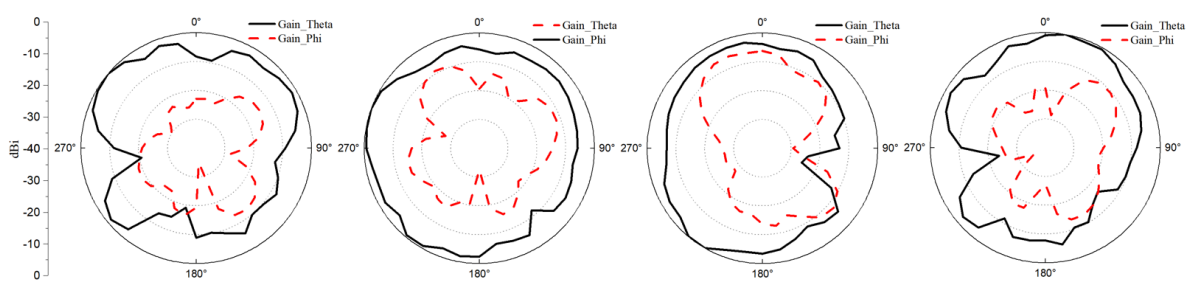

(b)

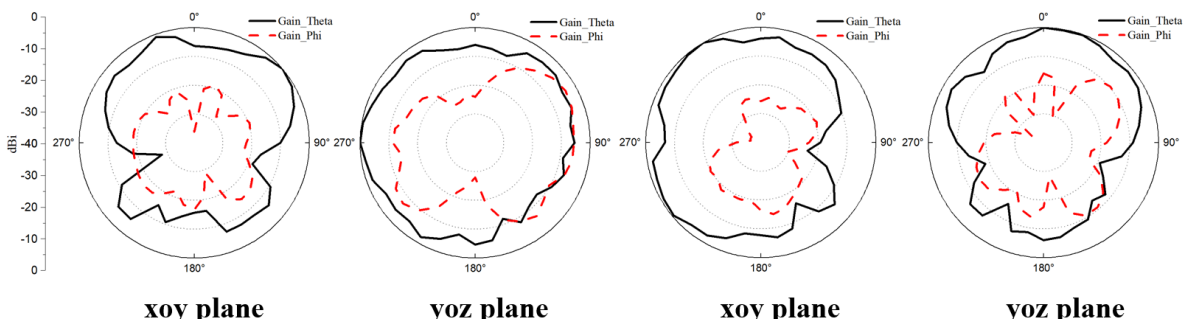

(c)

Figure 13. Measured 2D radiation patterns of Ant. 1 and Ant. 2 at (a) $3.5 \mathrm{GHz}$. (b) $4.9 \mathrm{GHz}$. (c) $5.5 \mathrm{GHz}$. 
In Table 1, the proposed eight-element antenna array not only has the advantage of the comprehensive performance, but also has a minimized size. Therefore, it can be well employed in the future triple-band ultra-thin $5 \mathrm{G}$ mobile phones.

Table 1. Comparison of the 5G MIMO smartphone antennas.

\begin{tabular}{|c|c|c|c|c|c|}
\hline Reference & $\begin{array}{c}\text { Operating Band } \\
(\mathrm{GHz})\end{array}$ & Isolation(dB) & ECC & Efficiency (\%) & $\operatorname{Size}\left(\mathrm{mm}^{3}\right)$ \\
\hline$[5]$ & $\begin{array}{c}3.4-3.8 \\
4.8-5(-6 \mathrm{~dB})\end{array}$ & $>15.5$ & $<0.06$ & $40-85$ & $15.2 \times 7 \times 0.8$ \\
\hline [6] & $\begin{array}{c}3.3-3.6 \\
4.8-5(-10 \mathrm{~dB}) \\
\end{array}$ & $>12$ & $<0.15$ & $>45$ & $10.6 \times 5.3 \times 0.8$ \\
\hline [7] & $\begin{array}{c}3.4-3.6 \\
4.8-5.1(-6 \mathrm{~dB}) \\
\end{array}$ & $>11.5$ & $<0.05$ & $40-85$ & $15 \times 7 \times 0.8$ \\
\hline [8] & $\begin{array}{c}3.4-3.6 \\
5.15-5.925(-10 \\
\mathrm{dB})\end{array}$ & $>11.2$ & $<0.08$ & $51-59$ & $10 \times 10 \times 0.8$ \\
\hline [9] & $\begin{array}{c}3.3-4.2 \\
4.8-5(-6 \mathrm{~dB})\end{array}$ & $>10$ & $<0.1$ & $53.8-79.1$ & $18.6 \times 7 \times 0.8$ \\
\hline [10] & $\begin{array}{c}3.4-3.6(-6 \mathrm{~dB}) \\
5.72-5.875(-10 \\
\mathrm{dB})\end{array}$ & $>17.1$ & $<0.045$ & $45-62$ & $14.9 \times 7 \times 0.8$ \\
\hline [11] & $\begin{array}{c}3.3-3.8 \\
4.8-5 \\
5.15-5.925(-10 \\
\mathrm{dB})\end{array}$ & $>18$ & $<0.06$ & $60-75$ & $15.8 \times 7 \times 0.8$ \\
\hline [13] & $3.3-6(-10 \mathrm{~dB})$ & $>10$ & $<0.1$ & $40-70$ & $13.9 \times 7 \times 0.8$ \\
\hline Pro. & $\begin{array}{c}3.3-3.8 \\
4.8-5 \\
5.15-5.925(-6 \mathrm{~dB})\end{array}$ & $>13$ & $<0.1$ & $>70$ & $6.5 \times 7 \times 0.8$ \\
\hline
\end{tabular}

\section{Conclusions}

In this paper, a minimized triple-band eight-element antenna array covering $3.3-3.8 \mathrm{GHz}$, 4.8-5 GHz, and 5.15-5.925 GHz has been proposed. The single antenna element consists of an S-shaped feeding strip and an L-shaped radiation strip on the metal frame. The size of a single antenna element is only $6.5 \mathrm{~mm} \times 7 \mathrm{~mm}$, which is the innovation point of this paper. The measured total efficiencies are larger than $70 \%$, and the isolations are better than $13 \mathrm{~dB}$, respectively. The antenna was verified by both simulation and measurement. The proposed antenna element has the advantage of comprehensive performance under the minimum size. Therefore, it is a good candidate for $5 \mathrm{G}$ mobile handsets.

Author Contributions: Conceptualization, J.H.; methodology, T.H.L.; data curation, Z.C.; investigation, Q.C.; writing —original draft preparation, J.H.; writing-review and editing, T.H.L. and G.L.; supervision and funding acquisition, G.L. All authors have read and agreed to the published version of the manuscript.

Funding: This work was funded in part by the Science and Technology Department of Zhejiang Province under Grant No. LGG19F010009, the National Natural Science Foundation of China under Grant No. 61671330, and Wenzhou Municipal Science and Technology Program under Grant No. C20170005 and No. 2018ZG019. The work of T. H. Loh was supported by the 2021-2025 National Measurement System Programme of the U.K. Government's Department for Business, Energy and Industrial Strategy, through the Science Theme Reference EMT21 of that Programme.

Data Availability Statement: The data presented in this study are available on request from the corresponding author. 
Conflicts of Interest: The authors declare no conflict of interest.

\section{References}

1. Sun, L.; Feng, H.; Li, Y.; Zhang, Z. Compact 5G MIMO Mobile Phone Antennas with Tightly Arranged Orthogonal-Mode Pairs. IEEE Trans. Antennas Propag. 2018, 66, 6364-6369. [CrossRef]

2. Ren, Z.; Zhao, A.; Wu, S. MIMO Antenna with Compact Decoupled Antenna Pairs for 5G Mobile Terminals. IEEE Antennas Wirel. Propag.. Lett. 2019, 18, 1367-1371. [CrossRef]

3. Chen, Y.; Zhang, C.; Lu, Y.; Yang, W.W.; Huang, J. Compact Dual-Polarized Base Station Antenna Array Using Laser Direct Structuring Technique. IEEE Antennas Wirel. Propag. Lett. 2021, 20, 78-82. [CrossRef]

4. Wang, H.; Zhang, R.; Luo, Y.; Yang, G. Compact Eight-Element Antenna Array for Triple-Band MIMO Operation in 5G Mobile Terminals. IEEE Access 2020, 8, 19433-19449. [CrossRef]

5. Hu, W.; Qian, L.; Gao, S.; Wen, L.H. Dual-Band Eight-Element MIMO Array Using Multi-Slot Decoupling Technique for 5G Terminals. IEEE Access 2019, 7, 153910-153920. [CrossRef]

6. Huang, J.; Dong, G.; Cai, Q.; Chen, Z.; Li, L.; Liu, G. Dual-Band MIMO Antenna for 5G/WLAN Mobile Terminals. Micromachines 2019, 12, 489. [CrossRef]

7. Guo, J.; Cui, L.; Li, C.; Sun, B. Side-Edge Frame Printed Eight-Port Dual-Band Antenna Array for 5G Smartphone Applications. IEEE Trans. Antennas Propag. 2018, 66, 7412-7417. [CrossRef]

8. Li, J.; Zhang, X.; Wang, Z.; Chen, X. Dual-Band Eight-Antenna Array Design for MIMO Applications in 5G Mobile Terminals. IEEE Access 2019, 7, 71636-71644. [CrossRef]

9. Cui, L.; Guo, J.; Liu, Y.; Sim, C. An 8-Element Dual-Band MIMO Antenna with Decoupling Stub for 5G Smartphone Applications. IEEE Antennas Wirel. Propag. Lett. 2019, 18, 2095-2099. [CrossRef]

10. Zou, H.; Li, Y.; Xu, B.; Chen, Y.; Jin, H.; Yang, G.; Luo, Y. Dual-Functional MIMO Antenna Array with High Isolation for 5G/WLAN Applications in Smartphones. IEEE Access 2019, 7, 167470-167480. [CrossRef]

11. Serghiou, D.; Khalily, M.; Singh, V.; Araghi, A.; Tafazolli, R. Sub-6 GHz Dual-Band $8 \times 8$ MIMO Antenna for 5G Smartphones. IEEE Antennas Wirel. Propag. Lett. 2020, 19, 1546-1550. [CrossRef]

12. Huang, J.; Dong, G.; Cai, J.; Li, H.; Liu, G. A Quad-Port Dual-Band MIMO Antenna Array for 5G Smartphone Applications. Electronics 2021, 10, 542. [CrossRef]

13. Sim, C.; Liu, H.; Huang, C. Wideband MIMO Antenna Array Design for Future Mobile Devices Operating in the 5G NR Frequency Bands N77/N78/N79 and LTE Band 46. IEEE Antennas Wirel. Propag. Lett. 2020, 19, 74-78. [CrossRef]

14. Abdullah, M.; Kiani, S.H.; Iqbal, A. Eight Element Multiple-Input Multiple-Output (MIMO) Antenna for 5G Mobile Applications. IEEE Access 2019, 7, 134488-134495. [CrossRef]

15. Zhang, X.; Li, Y.; Wang, W.; Shen, W. Ultra-Wideband 8-Port MIMO Antenna Array for 5G Metal-Frame Smartphones. IEEE Access 2019, 7, 72273-72282. [CrossRef]

16. Sun, L.; Li, Y.; Zhang, Z. Wideband Decoupling of Integrated Slot Antenna Pairs for 5G Smartphones. IEEE Trans. Antennas Propag. 2021, 69, 2386-2391. [CrossRef]

17. Chen, H.; Tsai, Y.; Sim, C.; Kuo, C. Broadband Eight-Antenna Array Design for Sub-6 GHz 5G NR Bands Metal-Frame Smartphone Applications. IEEE Antennas Wirel. Propag. Lett. 2020, 19, 1078-1082. [CrossRef]

18. Zhao, A.; Ren, Z. Size Reduction of Self-Isolated MIMO Antenna System for 5G Mobile Phone Applications. IEEE Antennas Wirel. Propag. Lett. 2019, 18, 152-156. [CrossRef]

19. Ren, A.; Liu, Y.; Yu, H.; Jia, Y.; Sim, C.; Xu, Y. A High-Isolation Building Block Using Stable Current Nulls for 5G Smartphone Applications. IEEE Access 2019, 7, 170419-170429. [CrossRef]

20. Li, Y.; Sim, C.; Luo, Y.; Yang, G. High-Isolation 3.5 GHz Eight-Antenna MIMO Array Using Balanced Open-Slot Antenna Element for 5G Smartphones. IEEE Trans. Antennas Propag. 2019, 67, 3820-3830. [CrossRef]

21. Peng, H.; Zhi, R.; Yang, Q.; Cai, J.; Wan, Y.; Liu, G. Design of a MIMO Antenna with High Gain and Enhanced Isolation for WLAN Applications. Electronics 2021, 10, 1659. [CrossRef]

22. Xu, Z.; Deng, C. High-Isolated MIMO Antenna Design Based on Pattern Diversity for 5G Mobile Terminals. IEEE Antennas Wirel. Propag. Lett. 2020, 19, 467-471. [CrossRef] 